\title{
BMJ Open Does an emergency access button increase the patients' satisfaction and feeling of safety with the out-of-hours health services? A randomised controlled trial in Denmark
}

Jonas Fynboe Ebert (D) , ${ }^{1}$ L Huibers, ${ }^{2}$ Bo Christensen, ${ }^{3}$ Helle Collatz Christensen, ${ }^{4,5}$ Morten Bondo Christensen ${ }^{2}$

To cite: Ebert JF, Huibers L, Christensen B, et al. Does an emergency access button increase the patients' satisfaction and feeling of safety with the out-ofhours health services? A randomised controlled trial in Denmark. BMJ Open 2020;10:e030267. doi:10.1136/ bmjopen-2019-030267

- Prepublication history and additional material for this paper are available online. To view these files, please visit the journal online (http://dx.doi org/10.1136/bmjopen-2019030267).

Received 06 March 2019 Revised 27 April 2020 Accepted 13 July 2020
Check for updates

(c) Author(s) (or their employer(s)) 2020. Re-use permitted under CC BY-NC. No commercial re-use. See rights and permissions. Published by BMJ.

For numbered affiliations see end of article.

Correspondence to Dr Jonas Fynboe Ebert; jonasebert@ph.au.dk

\section{ABSTRACT}

Objective To investigate if the option to bypass the telephone queue can increase satisfaction and feeling of safety in callers.

Design Randomised controlled parallel superiority trial. Data from questionnaire survey.

Setting Two out-of-hours $(\mathrm{OOH})$ services in Denmark. Participants 217510 citizens who called the $00 \mathrm{H}$ services between 4 September 2017 and 30 November 2017.

Randomisation Two-faze study period: First half with randomisation of participants based on their date of birth; even date randomised to intervention, uneven date randomised to control group. Second half with all participants included in intervention group.

Intervention Providing randomised callers (intervention group $n=146355$ ) with the option to bypass the telephone waiting line through an emergency access button (EAB), while the rest got the normal service (control group $\mathrm{n}=71155)$. All EAB users were invited to a questionnaire survey as well as random participants who did not use the EAB (of whom approximately $50 \%$ did not have the $E A B$ option).

Main outcome measures Satisfaction and feeling of safety in callers.

Results 2208 of 6704 (32.9\%) invited callers answered the questionnaire (intervention group $n=1415$ (users $n=621$, non-users $n=794$ ); control group $n=793$ ). The OR for answering in the two categories with highest satisfaction when provided with the EAB option was 1.34 (95\% Cl 1.07 to 1.68) for satisfaction with the waiting time, 1.21 (95\% Cl 0.91 to 1.60) for overall satisfaction and 1.46 (95\% Cl 1.12 to 1.89) for feeling of safety. Approximately $72 \%(441 / 621)$ of $E A B$ users reported that the EAB option increased their feeling of safety with the $00 \mathrm{H}$ services 'to a high degree' compared with 25\% (197/794) of callers who had the EAB option without using it.

Conclusions The EAB can provide fast access to $00 \mathrm{H}$ telephone advice in case of severe illness. It favours citizens perceived in most need of urgent healthcare and significantly increases both feeling of safety and patient satisfaction.
Strengths and limitations of this study

- This study investigates if an option to bypass the telephone waiting queue results in increased feeling of safety and higher satisfaction in callers to the outof-hours services

- A large number of questionnaires ensured high statistical power.

- Invitations were sent through a novel secure digital mailbox, which reduced the risk of recall bias.

- However, low response rates $(33 \%)$ increased the risk of selection bias.

Trial registration details NCT02572115 (5 0ctober 2015).

\section{INTRODUCTION}

The out-of-hours $(\mathrm{OOH})$ services provide telephone advice for citizens with acute health problems that are not life-threatening. These services are run by primary medical care in many countries. ${ }^{12}$ All callers are offered advice on the telephone, and some are triaged to an $\mathrm{OOH}$ clinic consultation, a home visit by a doctor or hospital admittance. ${ }^{34}$ All citizens calling the $\mathrm{OOH}$ services must queue for triage. In busy periods, the waiting time may exceed $25 \mathrm{~min}$ (personal communication with staff at the two Danish $\mathrm{OOH}$ services explored in this study). All callers enter the same call queue, regardless of the urgency of their health problem. ${ }^{5}$ Long waiting time for triage in the out-of-hours services carries a risk for callers with severe health problems as their condition may develop into a critical state while waiting.

Research on the $\mathrm{OOH}$ services has shown that approximately 5\% of callers perceive their condition as highly severe and that $2 \%$ to $3 \%$ of all callers are admitted directly to a 
hospital. ${ }^{6-9}$ Citizens often contact the $\mathrm{OOH}$ services due to worry, and long waiting time may produce a feeling of distress in callers when a health problem is perceived as severe. ${ }^{51011}$ Although the satisfaction with the $\mathrm{OOH}$ services is generally high, ${ }^{6}{ }^{12} 13$ long waiting may compromise the patient satisfaction and challenge the feeling of safety.

We tested an emergency access button (EAB) that allowed randomly selected callers to bypass the telephone waiting line in two OOH services in Denmark if the callers perceived their health problem as sufficiently severe to warrant immediate action. In a previous study, we reported a user rate of approximately 3\%. ${ }^{14}$ Another study evaluated the medical relevance (assessed by staff in the $\mathrm{OOH}$ services) of using the $\mathrm{EAB}^{15}$ ). In this study, we investigate if the $\mathrm{EAB}$ can increase the satisfaction with the $\mathrm{OOH}$ services and provide an increased feeling of safety in callers. We also aim to explore if selected descriptive characteristics of the population vary between users and non-users of the emergency access button and to test if factors such as perceived level of severity and triage outcome had an effect on the main outcome measures.

\section{METHODS}

\section{Design and setting}

We conducted a randomised controlled trial in accordance with the Consolidated Standards of Reporting Trials (CONSORT) guidelines at two $\mathrm{OOH}$ services using telephone triage: one in the Central Denmark Region and one in Copenhagen. Denmark has a gatekeeping system. Patients can only access the emergency department (ED) after triage by a general practitioner (GP) or a nurse. In four out of five regions in Denmark, the $\mathrm{OOH}$ services are provided by general practitioner cooperatives (GPC) in large-scale organisations. ${ }^{1}$ The fifth region (Copenhagen) offers a medical helpline (MH-1813), which is a publicly run call centre with telephone triage by nurses (approximately $80 \%$ ) and doctors with various medical specialities or in speciality training. In this paper, the GPs performing telephone triage at the GPC and the nurses/doctors performing telephone triage in the $\mathrm{MH}-1813$ are collectively referred to as triage professionals.

\section{Intervention}

All callers were routinely asked to type in the unique civil registration number (CRN), which includes the date of birth and a code for the sex of the patient whom the call concerned. Information on the intervention and opportunity to decline participation was provided through a message on the answering machine. Participants were then randomised into two arms: EAB option (intervention) or regular service (control) (figure 1). Randomisation was based on the CRN; patients with an even birth date got the $\mathrm{EAB}$ option (eg, birth date on $2^{\text {nd }}, 4^{\text {th }}$ or $6^{\text {th }}$ of a month), whereas patients with an uneven birth date got the regular service. After randomisation, the caller was informed of the estimated waiting time. If randomised to the intervention arm (EAB option), the caller was subsequently given the option to bypass the queue by pressing ' 9 ' if the caller perceived the condition to be sufficiently severe to warrant immediate action. The Danish message corresponded to the following: "If your condition is so severe that you find it necessary to get through straight away, you may press 9 and get first in line. Otherwise please wait." Bypassing the queue meant being placed at the front of the digital queue as the next caller to talk to a triage professional. As the callers were informed of the $\mathrm{EAB}$ option and could actively choose to use it, blinding to whether or not they were in the intervention group was not possible. Triage professionals were blinded, as they only found out about the patient using the button after the actual call was ended when answering the questionnaire directly after the contact. At this point, the triage professionals had already treated the patient without this knowledge and thus it did not affect the triage and hence not patient's satisfaction nor level of safety.

\section{Outcome measures}

We defined the following outcome measures prior to our study (table 1).

\section{Development of questionnaires}

The final post-intervention questionnaire comprised 25 questions (online supplementary appendix 1), of which 10 were developed by the authors and 15 had been validated in previous studies conducted by our research group. Questions addressed variables on sociodemographic information (eg, age, sex, education, ethnicity and job status), waiting time, self-perceived health, perceived urgency, caller satisfaction with the OOH services, ${ }^{6} 121316-18$ feeling of safety in callers, ${ }^{19}$ as we believe there is a close relation between feeling safe and being satisfied with the provided service. Also, we added the two-item generalised anxiety disorder (GAD-2), a short form of the GAD-7 questionnaire, which was developed in the USA to detect GAD in primary care patients. ${ }^{2021}$

The questionnaire was developed using existing questionnaires and literature. ${ }^{6} 2122$ Numerous feedback rounds were conducted with experienced researchers and GPs to produce a draft questionnaire. This draft questionnaire was pilot tested for 2 weeks in the GPC in the Central Denmark Region. ${ }^{23}$ After the pilot test, we conducted two focus group interviews with 13 participants. The interviews focussed on the callers' assessment of the $\mathrm{OOH}$ services provided by the GPC and their views on the questionnaire, including the wording of the questions in order to check the validity of the questionnaire. The interviews, which were performed by the main author assisted by a senior researcher, resulted in the rephrasing of two questions. Data from the pilot test was checked for ceiling effect and excessive amount of missing data or 'don't know' responses, which resulted in deletion of one question. 


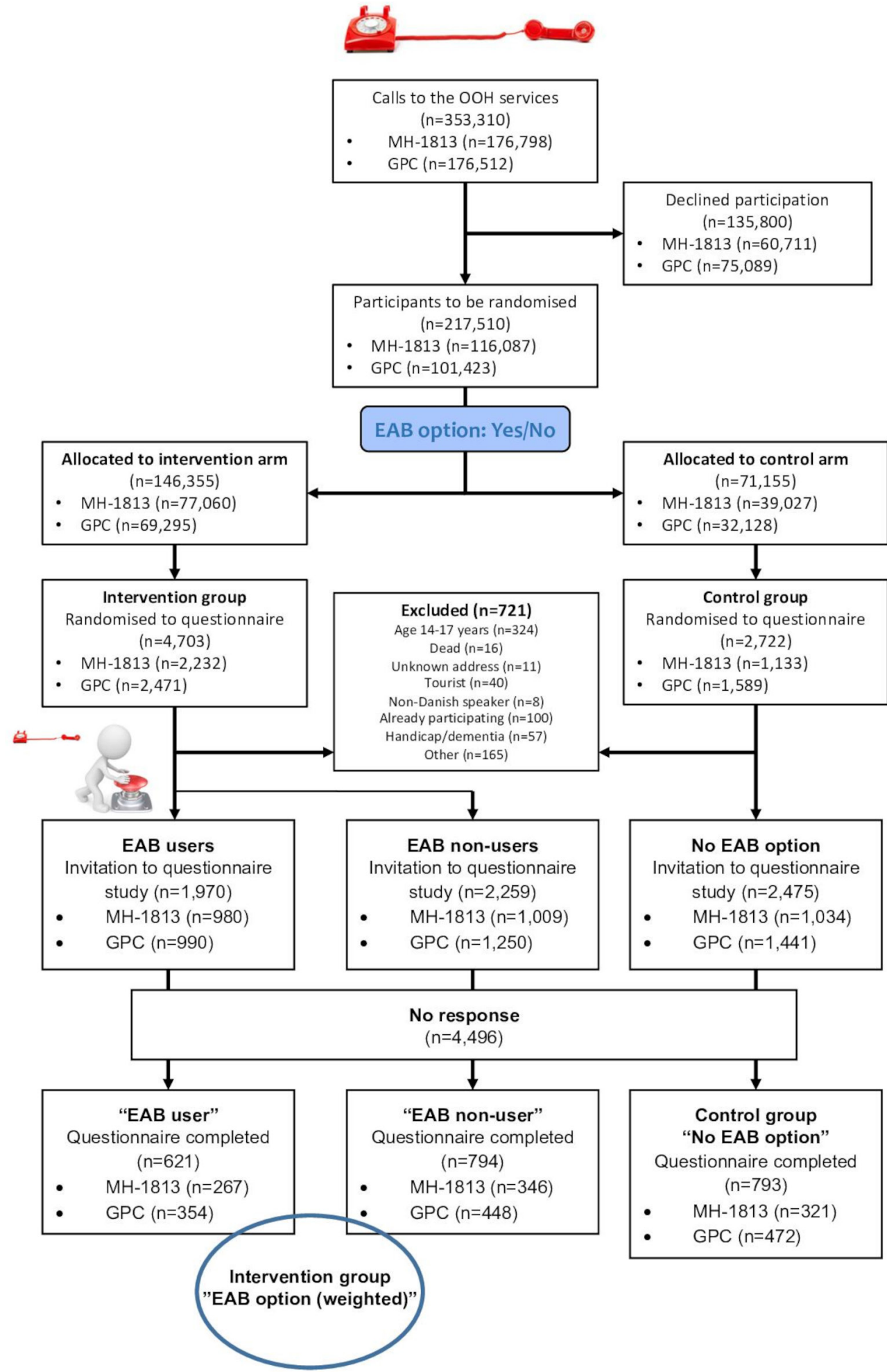

Figure 1 Flowchart of participants (Consolidated Standards of Reporting Trials). EAB,emergency access button; GPC, general practitioner cooperative; $\mathrm{MH}-1813$, medicalhelpline 1813; OOH; out-of-hours.

\section{Exclusion and inclusion criteria}

Table 2 shows the exclusion criteria for the study before and after dispatch of invitations. In total, 721 callers were excluded before dispatch of questionnaires. All completed questionnaires were included in the analyses. See figure 1 for CONSORT flowchart.

\section{Data collection}

Questionnaire data was collected from 4 September 2017 until 30 November 2017 in both settings. No major public holidays or health campaigns took place in the study period. When a caller accepted participation in the study, the CRN enabled us to retrieve the address of the patient 


\begin{tabular}{ll}
\hline Table 1 Outcome measures \\
\hline $\begin{array}{ll}\text { Primary outcome measures } & \text { Secondary outcome } \\
\text { measures }\end{array}$ \\
$\begin{array}{ll}\text { Caller feeling of safety } & \text { Frequency of caller } \\
\text { (intervention group vs control } & \text { characteristics (EAB-users vs } \\
\text { group) } & \text { non-users) }\end{array}$
\end{tabular}

Caller satisfaction all in all

with the contact (control

group vs non-intervention

group)

Caller satisfaction with

waiting time (control group vs

non-intervention group)

$\mathrm{EAB}$, emergency access button.

(or the legal guardian for children aged $<14$ years). Three subgroups received an invitation for the questionnaire survey: all callers from the intervention group who used the EAB (EAB users), a matching number of randomly selected callers in the intervention group who did not use the EAB (EAB non-users) and a matching number of randomly selected callers in the control group (no EAB option). The patients from the last two subgroups (EAB non-users and no EAB option) were included during the first 8 weeks of the study, whereas EAB users were included throughout the entire period. These different inclusion periods occurred because fewer callers than expected got the EAB option as approximately $15 \%$ refrained from typing in their CRN (and needed for the randomisation) and the participation rate was only approximately $65 \%$. Therefore, we decided to include 10 callers from the two subgroups without $\mathrm{EAB}$ use for every $\mathrm{EAB}$ user during the first 8 weeks. For the remaining 5 weeks, all participating callers were given the EAB option, including callers who refrained from typing in their CRN. Information on these callers was obtainable as the triage professional would ask the patient for the CRN and register it in the system. An included caller received only one questionnaire regarding the first contact (and not for any potential subsequent contacts).

Survey invitations were sent out by digital mailbox and surface mail. All citizens aged $\geq 15$ years in Denmark have a secure digital mailbox (free of charge), which is used for communication with the public authorities. Danish residents must check it regularly, and email or SMS (shortmessaging service) notifications are optional. A study from 2018 concluded that the digital mailbox is a low-cost, quick and secure way to invite Danish citizens to participate in a questionnaire study, which reduces the risk of recall bias, while the level of selection bias is similar to that of paper invitations. ${ }^{24}$ In our study, $88.5 \%$ had access to a digital mailbox and were invited through this method. The remaining part was invited by regular surface mail.

The digital invitation included a description of the study and a clickable hyperlink directing the citizen to a web-based questionnaire. Two digital reminders were sent 1 week and 2 weeks after the first invitation. The paper invitation included a description of the study, a hyperlink along with a 12-digit unique code, a paper questionnaire and a prepaid return envelope. One reminder was sent 3 weeks after the first invitation.

\section{Power calculation and sample size}

The main outcome measures were satisfaction and feeling of safety in callers (measured on a dichotomised 5-point Likert scale with the two most positive answers grouped against the three least positive answers). Based on the author group's experience with questionnaire studies we assumed a proportion of satisfaction and safety of 0.8 in the control arm and 0.9 in the EAB-use arm. We should include at least 266 individuals in each arm if we wanted to be able to detect a difference between the two arms with a power of $80 \%$ and a Bonferroni adjusted alpha

Table 2 Exclusion criteria before dispatch of invitations

\section{Excluded groups}

All citizens aged 14 to 17 years

Callers who had already received an invitation due to a previous contact

\begin{tabular}{|c|c|}
\hline Tourists & $\begin{array}{l}\text { Triage professional registered that caller was a tourist (registered by a } \\
\text { 'tourist CRN') }\end{array}$ \\
\hline Non-Danish speakers & Triage professional registered that the conversation was held in English \\
\hline $\begin{array}{l}\text { Citizens unfit for participation } \\
\text { (eg, dementia or handicap) }\end{array}$ & $\begin{array}{l}\text { Triage professional registered that the caller was too ill (eg, call made by } \\
\text { care assistant) }\end{array}$ \\
\hline Citizens with no registered address & No known address \\
\hline
\end{tabular}

CRN, civil registration number. 
value of $0.01667(=5 \% / 3)$ to adjust for multiple testing due to the three studied outcomes.

\section{Statistical methods}

The Pearson $\chi^{2}$ test was used to check for differences between subgroups in the distributions presented in table 3. We checked for differences in participant characteristics between subgroups within each setting. We divided the study population into five age groups based on a similar subdivision in a previous study by Moth $e t$ $a l .{ }^{6}$ The subdivision of employment status and education level was inspired by the categorisations used by Statistics Denmark and UNESCO. ${ }^{25}{ }^{26}$ Ethnicity was defined as Danish, western immigrant or non-western immigrant in accordance with the definitions by Statistics Denmark. ${ }^{25}$ A citizen was defined as a non-western immigrant if this person, or one or both parents, had been born outside Western Europe, an European Union country, Australia, New Zealand or the USA.

We aimed to investigate if the EAB had an influence on the levels of satisfaction and feeling of safety in callers. Therefore, we needed a subgroup that represented callers who got the EAB option without using it as well as a fraction of callers who chose to use the EAB. As we included all EAB users and only a random selection of callers who got the EAB option without using it, we could not simply combine all data for callers provided with the $\mathrm{EAB}$ option. In the intervention group, $3 \%$ used the EAB. ${ }^{14}$ Thus, $97 \%$ in the intervention group were $\mathrm{EAB}$ non-users. As we selected an equal number of EAB users and $\mathrm{EAB}$ non-users, we needed to apply a weight of 33 (100 divided by 3 ) to account for the lower number in the 'EAB non-users' subgroup. We called this weighted group 'EAB option'. We used the Pearson $\chi^{2}$ test with a RaoScott second order correction ${ }^{27}$ to analyse if there were differences between the control group (no EAB option) and the weighted intervention group (EAB option) in the distribution of responses regarding satisfaction and feeling of safety.

We dichotomised the responses regarding satisfaction and feeling of safety (with getting through on the telephone), which were scored on a 5-point Likert scale, and the responses regarding feeling of safety (with the $\mathrm{EAB}$ ), which were scored on a 4-point Likert scale, into two categories: positive and negative responses. The positive categories (satisfied and feeling safe) each contained the two most positive answers (very satisfied and satisfied; very safe and safe, to a high degree and to some degree). We tested the positive categories in each scale against the negative category in three multiple logistic regression models. The first model was crude (model 1 ). The second model was adjusted for age group, gender, ethnicity and living status (model 2). The third model was adjusted for the same factors as model 2 along with level of perceived severity, parent status, self-rated health, GAD-2 score and triage outcome (model 3 ). No adjustment for multiplicity was made.

\section{Patient and public involvement statement}

This research was done without involving patients in defining the research question, outcome measures or study design. Patients were invited to two focus group meetings to help adjust the questionnaire and the welcome message on the $\mathrm{OOH}$ telephone. Patients were not invited to comment on the design and to interpret the results. Patients were not invited to contribute to the writing or editing of the manuscript for readability or accuracy.

\section{RESULTS}

In total, 217510 out of $353310(61.6 \%)$ callers chose to participate in the study after contacting the $\mathrm{OOH}$ services. Of the $146355(67.3 \%)$ callers randomised to the intervention, 4229 citizens received a questionnaire and $1415(33.5 \%)$ answered. Of the 71155 allocated to non-intervention arm, 2475 citizens received a questionnaire and $793(32.0 \%)$ answered. The total response rate was $32.9 \%$ (2208/6704) (figure 1$)$.

\section{Background characteristics of respondents}

In the MH-1813, EAB users were generally significantly different from both subgroups of $\mathrm{EAB}$ non-users. In the GPC, no differences were seen between the three subgroups in the distribution of gender $(p=0.67)$, ethnicity $(p=0.41)$ and living status $(p=0.1)$. The subgroups 'no EAB option' and 'EAB non-users' were compared between the two settings and for both settings combined. Only four variables demonstrated significantly different distributions: ethnicity in MH-1813, GAD-2 score in the GPC and living status and job status in the two settings combined. A GAD-2 score of $>2$ was significantly more often seen in the 'EAB users' subgroup (20.9\%) than in the control group 'no EAB option' (12.2\%) and the subgroup 'EAB nonusers' $(10.7 \%) \quad(p<0.001)$. EAB users were significantly more frequently referred to a home visit, a hospital admittance or ambulance care than the other two subgroups (table 3).

Online supplementary appendix 2 provides an overview of a crude and a multiple logistic regression model of socio-demographic characteristics and questionnaire data related to EAB use for the callers in the intervention arm. When adjusting for all variables in the table, we found that non-western immigrant status (OR 1.79), low education (<10years OR 2.53), status as retired (OR 1.94) or unemployed (OR 2.07), and self-perceived severe, potentially life-threatening disease (OR 30.00) or severe, but not life-threatening disease (OR 5.02) were significantly related to higher likelihood of $\mathrm{EAB}$ use (online supplementary appendix 2).

\section{Satisfaction}

When comparing the distribution of responses to the two questions exploring satisfaction (specifically the distribution of responses between the study arms), we found that individuals in the intervention group 'EAB option' 
Table 3 Background information on questionnaire respondents stratified on setting and study group (\%), N=2208

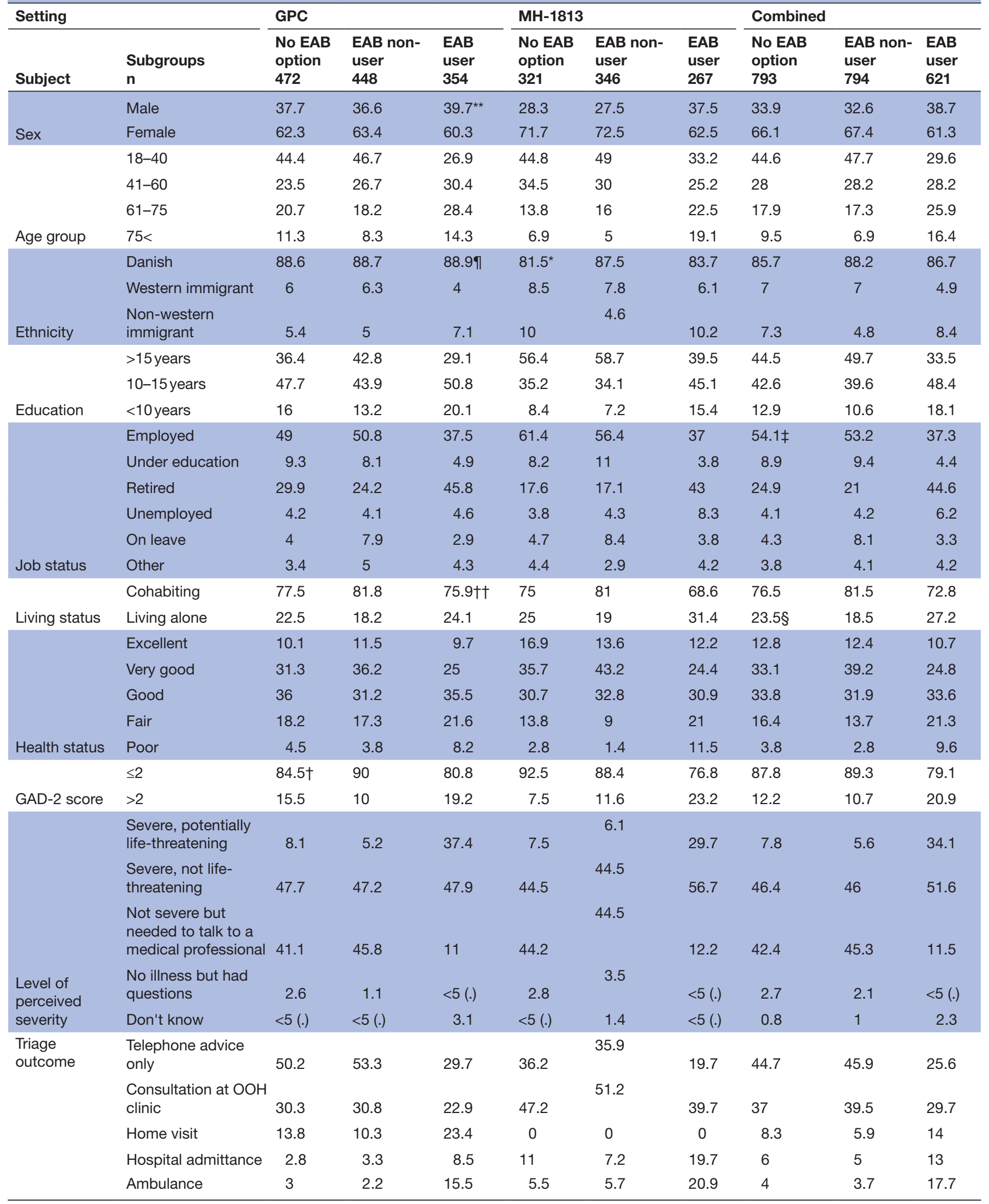


Table 3 Continued

\begin{tabular}{|c|c|c|c|c|c|c|c|c|c|c|}
\hline \multicolumn{2}{|l|}{ Setting } & \multicolumn{3}{|l|}{ GPC } & \multicolumn{3}{|l|}{ MH-1813 } & \multicolumn{3}{|c|}{ Combined } \\
\hline Subject & $\begin{array}{l}\text { Subgroups } \\
\mathrm{n}\end{array}$ & $\begin{array}{l}\text { No EAB } \\
\text { option } \\
472\end{array}$ & $\begin{array}{l}\text { EAB non- } \\
\text { user } \\
448\end{array}$ & $\begin{array}{l}\text { EAB } \\
\text { user } \\
354\end{array}$ & $\begin{array}{l}\text { No EAB } \\
\text { option } \\
321\end{array}$ & $\begin{array}{l}\text { EAB non- } \\
\text { user } \\
346\end{array}$ & $\begin{array}{l}\text { EAB } \\
\text { user } \\
267\end{array}$ & $\begin{array}{l}\text { No EAB } \\
\text { option } \\
793\end{array}$ & $\begin{array}{l}\text { EAB non- } \\
\text { user } \\
794\end{array}$ & $\begin{array}{l}\text { EAB } \\
\text { user } \\
621\end{array}$ \\
\hline
\end{tabular}

Results with less than five cases are not reported due to data protection regulations by the Danish Data Protection Agency. These cases are instead labelled ' $<5$ '. In the 'combined' section, this is also the case as a percentage would give away results labelled $n<5$.

Significant differences within each setting were found between the distributions in the groups 'no EAB option' and 'EAB non-user' in marked cases (analysed using the $\chi^{2}$ test): (a) $p=0.024$, (b) $p=0.014$, (c) $p=0.034$ and (d) $p=0.015$.

'EAB user' group is significantly different from the two other groups in all variables except for gender (e) $p=0.67$, ethnicity (f) $p=0.41$ and living status (g) $p=0.1$ in the GPC.

Interpretations

*Less respondents with Danish ethnicity in 'no EAB option' group compared to 'EAB non-user' group in MH-1813.

†More respondents in 'no EAB option' group with positive GAD-2 score (>2) compared to 'EAB non-user' group in the GPC.

¥Significant difference in distribution of job status between 'no EAB option' group and 'EAB non-user' group when settings are combined.

§More respondents living alone in 'no EAB option' group compared to 'EAB non-user' group when settings are combined.

ПNo significant difference in distribution of sex between the three study groups in GPC.

${ }^{* *}$ No significant difference in distribution of ethnicity between the three study groups in GPC.

$\dagger+$ No significant difference in distribution of ethnicity between the three study groups in GPC.

$\mathrm{EAB}$, emergency access button; GAD, generalised anxiety disorder; GPC, general practitioner cooperative; $\mathrm{MH}-1813$, medical helpline 1813; OOH, out-of-hours.

reported higher satisfaction levels for both waiting time $(\mathrm{p}=0.0092)$ and overall satisfaction $(\mathrm{p}=0.0073)$ (table 4$)$.

The satisfaction with waiting time was generally high. In the control group $72.2 \%$ of respondents reported to be 'satisfied' or 'very satisfied' compared with $78.2 \%$ in the intervention group. In the subanalysis of EAB users, $78.6 \%$ were 'satisfied' or 'very satisfied'. In fact, $46.7 \%$ of EAB users were 'very satisfied', which was significantly more than in the 'no EAB option' and the 'EAB option' groups (approximately $30 \%$ reported to be 'very satisfied').

This significant trend was also seen in the overall satisfaction with the contact. In all study groups, $83.9 \%$ to $87.1 \%$ reported to be 'satisfied' or 'very satisfied'. However, significantly more in the subgroup of EAB users reported to be 'very satisfied' (approximately 55\%) compared with the other subgroups (approximately 46\%) (table 4).

Additional subanalysis for patients with high perceived levels of severity showed that non-users were significantly less satisfied with waiting time compared with users (data not in table).

\section{Feeling of safety}

A significant difference was found in the distribution of responses between the non-intervention arm and the intervention arm in terms of feeling of safety concerning being able to reach the $\mathrm{OOH}$ service $(\mathrm{p}=0.0076)$. Significantly more $\mathrm{EAB}$ users $(71.9 \%)$ than $\mathrm{EAB}$ non-users $(25.0 \%)$ reported that the $\mathrm{EAB}$ option 'to a high degree' increased their feeling of safety $(\mathrm{p}<0.001)$ (table 4$)$.

\section{Multiple logistic regression}

The multiple logistic regression model confirmed that the $\mathrm{EAB}$ option in the intervention arm increased the satisfaction levels (unadjusted: waiting time OR 1.34 (95\% CI 1.07 to 1.68 ), overall OR 1.21 (95\% CI 0.91 to 1.60$)$ ) and the feeling of safety with getting through to the $\mathrm{OOH}$ service (unadjusted OR 1.46 (95\% CI 1.12 to 1.89)). This was seen in both the crude model and in the adjusted models (table 5 ).

\section{DISCUSSION \\ Principal findings}

The EAB option significantly increased the callers' satisfaction with the $\mathrm{OOH}$ service and their feeling of safety due to increased accessibility to the $\mathrm{OOH}$ service. Moreover, $25 \%$ of callers with the $\mathrm{EAB}$ option and $72 \%$ of $\mathrm{EAB}$ users reported that the $\mathrm{EAB}$ option increased their feeling of safety to a high degree.

\section{Strengths and limitations}

A strength of this study was the large number of responses, which ensured good statistical power. We also managed to reduce the risk of recall bias by sending out questionnaire invitations through a secure digital mailbox ${ }^{24}$ to most of the population (approximately 90\%), which implied that the questionnaire was received within 1 to 3 days after the contact.

A limitation was the participation rate of approximately $62 \%$ and the response rate of approximately $33 \%$, which increased the risk of selection bias. We did not perform any analyses of non-participants because of lack of consent. If non-participants more often suffered from urgent health problems, this could have led to higher frequency of $\mathrm{EAB}$ use and thereby reduced the estimates. The characteristics of the study population in our data were similar to the characteristics reported in a previous study based on register data concerning age, education and employment status, ${ }^{14}$ which suggests that the two populations are similar. However, more women, fewer non-western immigrants and fewer with low education answered the questionnaire in this study compared with the previous study. ${ }^{14}$ When comparing the group with no EAB option to $\mathrm{EAB}$ non-users, we found significant differences in the 
Table 4 Responses regarding satisfaction and feeling of safety stratified on study group ( $N=2208)$

\begin{tabular}{|c|c|c|c|c|c|c|}
\hline $\mathbf{n}$ & $\begin{array}{l}\text { No EAB option } \\
793\end{array}$ & $\begin{array}{l}\text { EAB option* } \\
\text { (weighted) }\end{array}$ & $\begin{array}{l}\text { EAB non-users } \\
794\end{array}$ & $\begin{array}{l}\text { EAB users } \\
621\end{array}$ & $P$ value & Missings/N (\%) \\
\hline Waiting time on telephone & $\mathrm{N}(\%)$ & (\%) & $\mathrm{N}(\%)$ & $\mathrm{N}(\%)$ & & \\
\hline Very satisfied & $235(29.7)$ & (30.3) & $236(29.9)$ & $286(46.7)$ & & \\
\hline Satisfied & $337(42.6)$ & $(47.9)$ & $381(48.3)$ & $195(31.9)$ & & \\
\hline $\begin{array}{l}\text { Neither satisfied nor } \\
\text { dissatisfied }\end{array}$ & $119(15.0)$ & (13.5) & $107(13.6)$ & $54(8.8)$ & & \\
\hline Dissatisfied & $66(8.3)$ & $(6.2)$ & $49(6.2)$ & $38(6.2)$ & & \\
\hline Very dissatisfied & $27(3.4)$ & (2.0) & $15(1.9)$ & $30(4.9)$ & & \\
\hline Don't know/not relevant & $7(0.9)$ & $(0.2)$ & $<5()$. & $9(1.5)$ & 0.0092 & $16 / 2208(0.72)$ \\
\hline \multicolumn{7}{|l|}{ All in all with the contact } \\
\hline Very satisfied & $364(46.0)$ & $(46.2)$ & $363(45.9)$ & $337(54.8)$ & & \\
\hline Satisfied & $300(37.9)$ & $(40.9)$ & $325(41.1)$ & $183(29.8)$ & & \\
\hline $\begin{array}{l}\text { Neither satisfied nor } \\
\text { dissatisfied }\end{array}$ & $59(7.5)$ & $(5.7)$ & $45(5.7)$ & $41(6.7)$ & & \\
\hline Dissatisfied & $30(3.8)$ & (3.1) & $24(3.0)$ & $21(3.4)$ & & \\
\hline Very dissatisfied & $29(3.7)$ & $(4.1)$ & $32(4.1)$ & $28(4.6)$ & & \\
\hline Don't know/not relevant & $9(1.1)$ & $(0.1)$ & $<5()$. & $5(0.8)$ & 0.0073 & $12 / 2208(0.54)$ \\
\hline \multicolumn{7}{|c|}{ Do you feel safe about being able to reach the $\mathrm{OOH}-\mathrm{PC}$ service? } \\
\hline Very safe & $208(26.3)$ & $(28.5)$ & $225(28.4)$ & $199(32.3)$ & & \\
\hline Safe & $420(53.1)$ & $(56.0)$ & $444(56.1)$ & $311(50.5)$ & & \\
\hline Neither safe nor unsafe & $106(13.4)$ & (11.2) & $89(11.3)$ & $54(8.8)$ & & \\
\hline Unsafe & $41(5.2)$ & (3.1) & $24(3.0)$ & $30(4.9)$ & & \\
\hline Very unsafe & $12(1.5)$ & $(0.4)$ & $<5()$. & $11(1.8)$ & & \\
\hline Don't know/not relevant & $<5()$. & $(0.8)$ & $6(0.8)$ & $11(1.8)$ & 0.0076 & $10 / 2208(0.45)$ \\
\hline \multicolumn{7}{|c|}{ Did the EAB option increase your feeling of safety? } \\
\hline To a high degree & - & - & $197(25.0)$ & $441(71.9)$ & & \\
\hline To some degree & - & - & $231(29.3)$ & $111(18.1)$ & & \\
\hline In a lesser degree & - & - & $85(10.8)$ & $10(1.6)$ & & \\
\hline Not at all & - & - & $116(14.7)$ & $20(3.3)$ & & \\
\hline Don't know/not relevant & - & - & $159(20.2)$ & $31(5.1)$ & $<0.001$ & 14/1415 (0.99) \\
\hline
\end{tabular}

Results with less than five cases are not reported due to data protection regulations by the Danish Data Protection Agency. These cases are instead labelled ' $n<5$ '.

'EAB use' group is significantly different from the other groups.

* $E A B$ option' group is a weighted group that also contains $E A B$ users to mimic an intervention group with $3 \%$ EAB users. $P$ values compare the distribution of answers between 'No EAB option' and 'EAB option' using the Pearson $\chi^{2}$ test with a Rao-Scott correction.

$\mathrm{EAB}$, emergency access button; $\mathrm{OOH}$, out-of-hours; $\mathrm{PC}$, practitioner cooperative.

distribution of four variables: ethnicity in the MH-1813, GAD-2 score in the GPC and living status and job status for both settings combined. We expect the risk of selection bias to be limited as these socio-demographic variables are known to not consistently influence the callers' satisfaction. ${ }^{6} 18$

Several studies have explored patient satisfaction with the $\mathrm{OOH}$ services. ${ }^{28-30}$ Most questionnaires use several scales to measure patient satisfaction with different aspects of provided services, and many are designed to be used as a repeated measure over time. We chose to include only two single-item questions as they depended on the choice of using the EAB. Our method of using single items to measure satisfaction may not give a complete picture of the patient satisfaction with the EAB.

Another limitation of the study was the potential bias from the asymmetrical data collection period. The data on the two groups that did not use the $\mathrm{EAB}$ was collected during the first 8 weeks, while the data on the group that used the EAB was collected throughout the entire study period of 13 weeks. However, as no public holidays or major health campaigns that could have influences $\mathrm{OOH}$ service user rates occurred during the data collection period, we expect minimal selection bias from this variation.

Moreover, we acknowledge that there is a loss of power when going from a Likert scale to a binary outcome. 


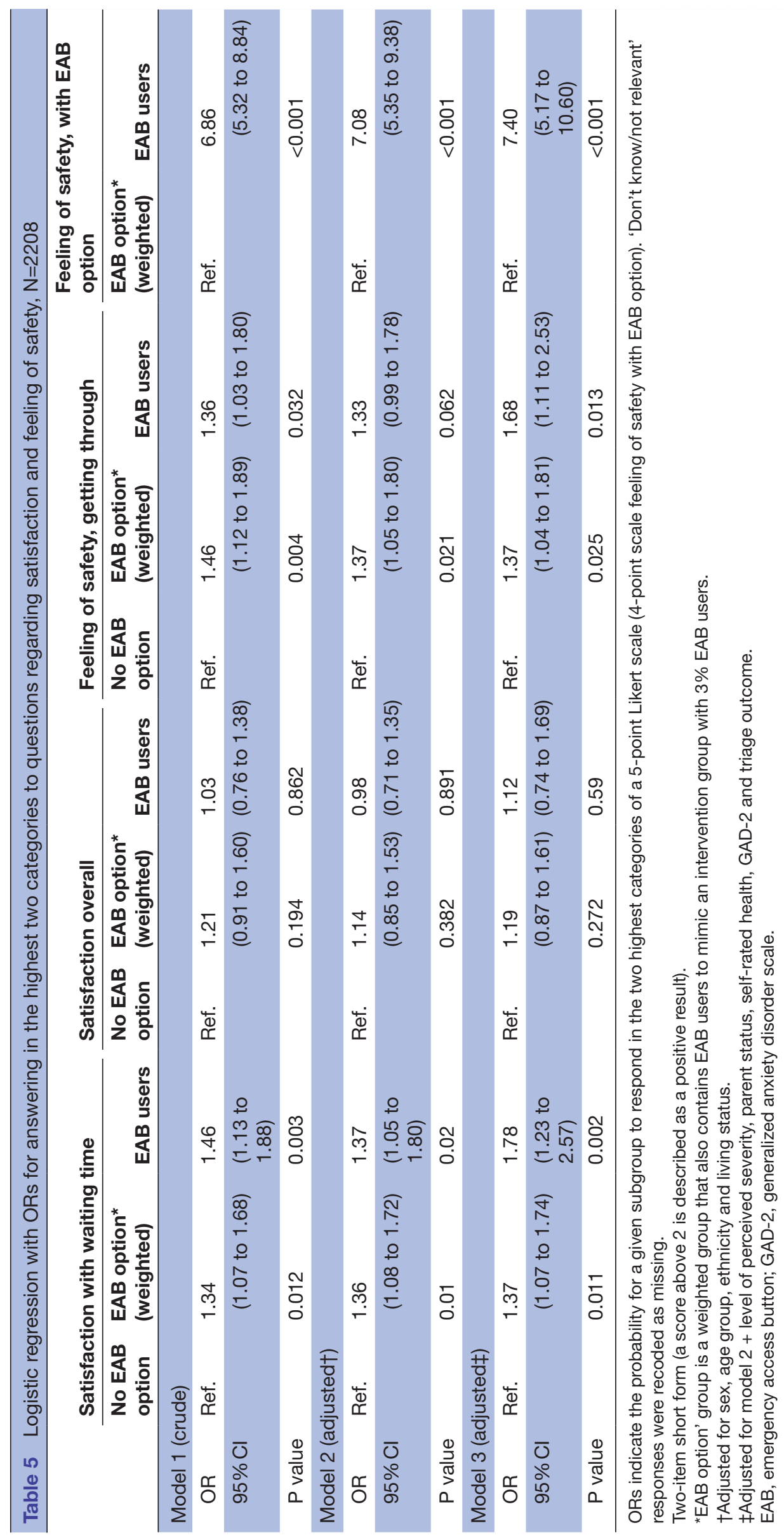


However, as the subgroups contained all respondents from both settings, we achieved more than the necessary amount of responses needed as described in the power calculations

\section{Findings in relation to other studies}

No other studies have investigated patient experiences with an $\mathrm{EAB}$ and the potential impact on patient satisfaction. The satisfaction with the $\mathrm{OOH}$ services is already high. ${ }^{6121718}$ Moth et al ${ }^{6}$ reported a satisfaction level of approximately $80 \%$, which is comparable with the level found in our study as $84 \%$ to $87 \%$ of respondents were (very) satisfied. Such high baseline satisfaction levels can make it difficult to detect any significant additional effects of an intervention, although respondents in our weighted 'EAB option' intervention group showed significantly higher satisfaction levels than respondents in the control group. Furthermore, the subgroup of callers who were offered the $\mathrm{EAB}$ without using it were not less satisfied than the rest. This is a relevant finding as some patients might have felt dissatisfied with others cutting the line. Several factors have previously been associated with level of satisfaction, such as age, self-perceived health, waiting time and triage outcome. ${ }^{1318} 3132$ After adjustment for these factors, the ORs were similar to the ORs of the crude model in our study.

The EAB provides callers with an option to bypass the queue in case of perceived acute severe illness. This may increase what Lovink et al described as 'feeling of safety' by providing callers with some control of the situation. ${ }^{19}$ To our knowledge, the literature is scarce on patients' feeling of safety in connection with the $\mathrm{OOH}$ telephone services; the quality of these services is predominantly measured by level of patient satisfaction. ${ }^{28-30}$ However, EAB users were older, more often retired/unemployed, and more often anxious people of poorer health than the other groups. Citizens with these socio-demographic traits have previously been found to exhibit more frequent help-seeking ${ }^{33}$ and higher degrees of worry, ${ }^{35}$ these citizens could thus be more vulnerable and have a stronger need for increased feeling of safety, which the $\mathrm{EAB}$ provides. ${ }^{15}$ Moreover, reporting an increased feeling of safety when using the $\mathrm{EAB}$ option could also be subject to social desirability bias, ${ }^{36}$ and could be related to the higher proportion of $\mathrm{EAB}$ users triaged to an increased service level (ie, EAB users were significantly more frequently referred to a home visit, a hospital admittance or ambulance care than the other two subgroups). However, the differences found seem robust; $72 \%$ of $\mathrm{EAB}$ users reported to have an increased feeling of safety because of the $\mathrm{EAB}$ option compared with $25 \%$ of non-users.

\section{Implications for future research and clinical practice}

The $\mathrm{EAB}$ is intended to provide fast access to a healthcare professional in the $\mathrm{OOH}$ service for patients in urgent need of medical assistance. Approximately $3 \%$ of callers used the $\mathrm{EAB},{ }^{14}$ and only approximately $23 \%$ of this use is assessed as 'not relevant' by triage professionals. ${ }^{15}$ The $\mathrm{EAB}$ provides an increased satisfaction and feeling of safety. The main challenge is to get severely ill callers to use the EAB and yet prevent misuse of the option. A future qualitative study design could investigate if the $\mathrm{EAB}$ option changes the behaviour of $\mathrm{OOH}$ service users with regards to reasons for contacting the service and use of the EAB.

Future studies could explore what happens to EAB users after the $\mathrm{OOH}$ call, specifically in terms of further contacts to the healthcare system and later diagnoses. It also seems relevant to study the patients who chose not to use the EAB although such use would have been considered medically relevant. These individuals should be identified and potential negative effects on patient outcome should be explored. This group may benefit from tailored interventions to support the most appropriate health behaviour in the future.

As a result of this project, the $\mathrm{OOH}$ services in the Central Denmark Region and the Capital Region of Denmark have decided to implement the EAB.

\section{CONCLUSION}

This study shows that the option to bypass the telephone waiting queue increases the satisfaction with the $\mathrm{OOH}$ services in callers. This is seen despite high satisfaction levels before the intervention. Furthermore, the $\mathrm{EAB}$ option provides most callers with a higher feeling of safety due to increased accessibility to the $\mathrm{OOH}$ service. More than $50 \%$ of callers who had the EAB option reported that the option gave an increased feeling of safety. Both the level of satisfaction and the feeling of safety in EAB users, which constitute a more worried and vulnerable patient population, were significantly higher than the level in all other callers.

We believe that the EAB is an improvement to the Danish $\mathrm{OOH}$ services and that it could easily be incorporated into the $\mathrm{OOH}$ services in other countries with similar $\mathrm{OOH}$ service organisation.

\section{Author affiliations}

${ }^{1}$ Research Unit for General Practice, Aarhus Universitet Health, Aarhus, Denmark

${ }^{2}$ Research Unit for General Practice, Aarhus Universitet, Aarhus, Denmark

${ }^{3}$ Public Health, Aarhus University, Aarhus C, Denmark

${ }^{4}$ Copenhagen Emergency Medical Services, Copenhagen, Denmark

${ }^{5}$ Danish Clinical Quality Program (RKKP), National Clinical Registries, Frederiksberg, Denmark

Acknowledgements The author group would like to thank the staff at the general practitioner cooperatives in the Central Denmark Region and the Prehospital Unit in Copenhagen for participating in the study. We would also like to thank Freddy $\mathrm{K}$ Lippert, CEO of the Emergency Medical Service in Copenhagen, for his devoted help, support and dedication throughout the process, specifically for the delivery of data and manpower, which contributed to the success of this project. The authors received statistical help from Henrik Schou Pedersen.

Contributors The corresponding author confirms that all listed authors meet the authorship criteria and that no other meeting the criteria have been omitted. JFE designed the study, performed the data collection, interpreted the data and drafted the manuscript. $\mathrm{LH}, \mathrm{MBC}$ and BC participated in designing the study and interpretation of the data, and critically revised the manuscript. $\mathrm{HC}$ critically revised the manuscript. All authors read and approved the final manuscript.

Funding We thankfully acknowledge the funding provided for this study by TrygFonden grant number 104893, the Foundation for Primary Healthcare Research of the Central Denmark Region (Praksisforskningsfonden) grant number 1-15-172-13-09, the Committee of Multi-practice Studies in General Practice (MPU) grant number MPU 11-2015, and the Committee for Quality Improvement and Continuing Medical Education (Kvalitets- og Efteruddannelsesudvalget) of the Central Denmark Region grant number 1-30-72-200-15. The Emergency Medical Services in 
the Capital Region have received unrestricted research grants from the Laerdal Foundation.

Competing interests None declared.

Patient consent for publication Not required.

Provenance and peer review Not commissioned; externally peer reviewed.

Data availability statement Data are available upon reasonable request. The authors are not authorised to share non-aggregated data with a third party. However, data are available from the corresponding author on reasonable request.

Supplemental material This content has been supplied by the author(s). It has not been vetted by BMJ Publishing Group Limited (BMJ) and may not have been peer-reviewed. Any opinions or recommendations discussed are solely those of the author(s) and are not endorsed by BMJ. BMJ disclaims all liability and responsibility arising from any reliance placed on the content. Where the content includes any translated material, BMJ does not warrant the accuracy and reliability of the translations (including but not limited to local regulations, clinical guidelines, terminology, drug names and drug dosages), and is not responsible for any error and/or omissions arising from translation and adaptation or otherwise.

Open access This is an open access article distributed in accordance with the Creative Commons Attribution Non Commercial (CC BY-NC 4.0) license, which permits others to distribute, remix, adapt, build upon this work non-commercially, and license their derivative works on different terms, provided the original work is properly cited, appropriate credit is given, any changes made indicated, and the use is non-commercial. See: http://creativecommons.org/licenses/by-nc/4.0/.

\section{ORCID iD}

Jonas Fynboe Ebert http://orcid.org/0000-0001-5936-6662

\section{REFERENCES}

1 Grol R, Giesen P, van Uden C. After-Hours care in the United Kingdom, Denmark, and the Netherlands: new models. Health Aff 2006;25:1733-7.

2 Huibers L, Giesen P, Wensing M, et al. Out-Of-Hours care in Western countries: assessment of different organizational models. BMC Health Serv Res 2009;9:105-6963-9-105.

3 Christensen MB, Olesen F. Out of hours service in Denmark: evaluation five years after reform. BMJ 1998;316:1502-5.

4 Keizer E, Smits M, Peters Y, et al. Contacts with out-of-hours primary care for nonurgent problems: patients' beliefs or deficiencies in healthcare? BMC Fam Pract 2015;16:157-015-0376-9.

5 Poole R, Gamper A, Porter A, et al. Exploring patients' self-reported experiences of out-of-hours primary care and their suggestions for improvement: a qualitative study. Fam Pract 2011;28:210-9.

6 Moth G, Flarup L, Christensen MB. Kontakt- og sygdomsmønsteret i lægevagten LV-KOS 2011 [Survey on reasons for encounters and disease patterns in $\mathrm{OOH}$ primary care LV-KOS 2011. Aarhus Forskningsenheden for Almen Praksis (Research Unit for General Practice); 2012.

7 Moth G, Huibers L, Christensen MB, et al. Out-Of-Hours primary care: a population-based study of the diagnostic scope of telephone contacts. Fam Pract 2016;33:504-9.

8 Zakariassen E, Hansen E, Hunskaar S. Incidence of emergency contacts (red responses) to Norwegian emergency primary healthcare services in 2007 - a prospective observational study. Scand J Trauma Resusc Emerg Med 2009;17:30-7241-17-30.

9 Plat FM, Peters YAS, Loots FJ, et al. Ambulance dispatch versus general practitioner home visit for highly urgent out-of-hours primary care. Fam Pract 2018;35:440-5.

10 Hugenholtz M, Bröer C, van Daalen R. Apprehensive parents: a qualitative study of parents seeking immediate primary care for their children. Br J Gen Pract 2009;59:173-9.

11 Kallestrup P, Bro F. Parents' beliefs and expectations when presenting with a febrile child at an out-of-hours general practice clinic. Br J Gen Pract 2003;53:43-4.

12 Smits M, Huibers L, Oude Bos A, et al. Patient satisfaction with outof-hours GP cooperatives: a longitudinal study. Scand J Prim Health Care 2012;30:206-13.
13 Kelly M, Egbunike JN, Kinnersley P, et al. Delays in response and triage times reduce patient satisfaction and enablement after using out-of-hours services. Fam Pract 2010;27:652-63.

14 Ebert JF, Huibers L, Christensen B, et al. Giving callers the option to bypass the telephone waiting line in out-of-hours services: a comparative intervention study. Scand J Prim Health Care 2019:1-8.

15 Ebert JF, Huibers L, Christensen B, et al. Do callers to out-of-hours care misuse an option to jump the phone queue? Scand J Prim Health Care 2019;37:207-17.

16 Carr-Bains S, Nightingale AL, Ballard KD. Patients' experiences and satisfaction with out-of-hours GP home visiting provided by a GP cooperative. Fam Pract 2011;28:88-92.

17 Howard M, Goertzen J, Hutchison B, et al. Patient satisfaction with care for urgent health problems: a survey of family practice patients. Ann Fam Med 2007:5:419-24.

18 Danielsen K, Bjertnaes OA, Garratt A, et al. The association between demographic factors, user reported experiences and user satisfaction: results from three casualty clinics in Norway. BMC Fam Pract 2010;11:73.

19 Lovink MH, Kars MC, de Man-van Ginkel JM, et al. Patients' experiences of safety during haemodialysis treatment--a qualitative study. J Adv Nurs 2015;71:2374-83.

20 Kroenke K, Spitzer RL, Williams JBW, et al. Anxiety disorders in primary care: prevalence, impairment, comorbidity, and detection. Ann Intern Med 2007;146:317-25.

21 Spitzer RL, Kroenke K, Williams JBW, et al. A brief measure for assessing generalized anxiety disorder: the GAD-7. Arch Intern Med 2006;166:1092-7.

22 Ware JE, Sherbourne CD. The mos 36-item short-form health survey (SF-36). I. conceptual framework and item selection. Med Care 1992;30:473-83.

23 Ebert JF, Huibers L, Lippert FK, et al. Development and evaluation of an "emergency access button" in Danish out-of-hours primary care: a study protocol of a randomized controlled trial. BMC Health Serv Res 2017;17:379-017-2308-y.

24 Ebert JF, Huibers L, Christensen B, et al. Paper- or web-based questionnaire invitations as a method for data collection: crosssectional comparative study of differences in response rate, completeness of data, and financial cost. J Med Internet Res 2018;20:e24.

25 Statistics D. Statistics Denmark, 2018. Available: https://www.dst.dk/ en

26 Unesco. International standard classification of education ISCED 2011, 2011. Available: http://uis.unesco.org/sites/default/files/ documents/international-standard-classification-of-education-isced2011-en.pdf

27 JNK R, Cott AJ. On Chi-Squared tests for Multiway contingency tables with cell proportions estimated from survey data. Ann Statist 1984;12:46-60.

28 Campbell JL, Dickens A, Richards SH, et al. Capturing users' experience of UK out-of-hours primary medical care: piloting and psychometric properties of the out-of-hours patient questionnaire. Qual Saf Health Care 2007;16:462-8.

29 Garratt AM, Danielsen K, Hunskaar S. Patient satisfaction questionnaires for primary care out-of-hours services: a systematic review. Br J Gen Pract 2007;57:741-7.

30 Allemann Iseli M, Kunz R, Blozik E. Instruments to assess patient satisfaction after teleconsultation and triage: a systematic review. Patient Prefer Adherence 2014;8:893-907.

31 Crow R, Gage H, Hampson S, et al. The measurement of satisfaction with healthcare: implications for practice from a systematic review of the literature. Health Technol Assess 2002;6:1-244.

32 van Uden CJT, Ament AJHA, Hobma SO, et al. Patient satisfaction with out-of-hours primary care in the Netherlands. BMC Health Serv Res 2005;5:6.

33 Vedsted P, Christensen MB. Frequent attenders in general practice care: a literature review with special reference to methodological considerations. Public Health 2005;119:118-37.

34 Greenfield G, Ignatowicz A, Gnani S, et al. Staff perceptions on patient motives for attending GP-led urgent care centres in London: a qualitative study. BMJ Open 2016;6:e007683.

35 Gamst-Jensen H, Huibers L, Pedersen K, et al. Self-Rated worry in acute care telephone triage: a mixed-methods study. Br J Gen Pract 2018;68:e197-203.

36 Althubaiti A. Information bias in health research: definition, pitfalls, and adjustment methods. J Multidiscip Healthc 2016;9:211-7. 